\title{
REFERENCES
}

Cox F. J. (1942) Anterior dislocation of distal extremity of the ulna-report of a case. Surgery 12, 41.

Curr J. F. \& Coe W. A. (1946) Dislocation of the inferior radio-ulnar joint. British fournal of Surgery 34, 74.

Essex-Lopresti P. (1950) Fractures of the radial head with inferior radio-ular dislocations. Fournal of Bone and foint Surgery 32, 745.

Essex-Lopresti P. (1951) Fracture of radial head with distal ulnar dislocation-report of two cases. fournal of Bone and foint Surgery 33, 244-7.

McDougall A. \& White J. (1957) Subluxation of inferior radio-ulnar joint complicating fractures of radial head. Fournal of Bone and foint Surgery 39, 278-87.

Mikic Z. D. J. (1975) Galeazzi fracture-dislocations. Fournal of Bone and foint Surgery 57, 1071-82.

Rose-Innes A. P. (1960) Anterior dislocation of the ulna at the inferior radio-ulnar joint. fournal of Bone and foint Surgery 42, 515-21.

\section{re Myocardial infarction and ventricular rupture}

\section{Sir}

Ventricular rupture may occur as a consequence of myocardial infarction, but it is rarely thought of and usually fatal. However, the condition is now treatable under certain circumstances although early detection is essential. We have recently had two cases which illustrate the problems this condition may pose in the accident and emergency department.

A 61-year-old female was brought into the department complaining of severe right lower chest and upper abdominal pain. Three years previously she had had a myocardial infarction. She had been attending the out-patient department with right upper quadrant pain but all investigations had been negative. She was shocked. Blood pressure was unrecordable. Heart sounds were quiet but present. Chest X-ray was normal. Electrocardiograph showed pathological $Q$ waves in lead III. The central venous pressure was recorded as $23 \mathrm{~mm}$ of water. A diagnosis of massive pulmonary embolism was made and she was transferred to the cardiac laboratory for catheterization, but she suffered a cardiac arrest while in the laboratory and resuscitation was unsuccessful. A post mortem examination revealed $200 \mathrm{ml}$ of clotted blood in the pericardial sac with a full thickness infarct in the anterior wall of the left ventricle. There was a small tortuous passage from the cavity of the ventricle to the epicardium.

- The second case was a 64-year-old male who collapsed in the diabetic department. He had had increasing chest pain over the previous 6 weeks. On arrival in the accident and emergency department he had no cardiac output and both pupils were dilated. Electrocardiograph showed asystole and resuscitation was unsuccessful. Post-mortem examination revealed $200 \mathrm{ml}$ of blood in the pericardial cavity with a recent infarct in the inferior wall of the right ventricle. There was a $0.5-\mathrm{cm}$ hole in the free wall of the right ventricle.

Rupture of a free wall of the heart is not uncommon; it accounts for $10 \%$ of deaths following myocardial infarction (Rasmussen et al., 1979). A large perforation is rapidly fatal. However, if there is only a small breach in the ventricular wall then the patient may survive if the condition is quickly recognized and treated (Parr et al., 1981).

The major clinical signs of cardiac tamponade are hypotension, pulsus paradoxus, quiet or absent heart sounds and markedly raised jugular venous pressure. Ultrasound is the investigation most likely to confirm the diagnosis but false negatives have been reported due to the presence of blood clot. Chest $x$-ray is often normal. The electrocardiogram may show tall peaked $T$ waves in the precordial leads or the reversal of pre-existing $\mathrm{T}$ wave inversion. 
However, if the patient is in extremis and cardiac tamponade is suspected then $\mathrm{T}$ pericardiocentesis under electrocardiographic control should be performed $\frac{\mathbb{\Phi}}{0}$ immediately. This will confirm the diagnosis, allow removal of fluid (often with 3 dramatic improvement in the condition of the patient) and will allow time for emergency ? thoracotomy and definitive treatment of the cardiac perforation.

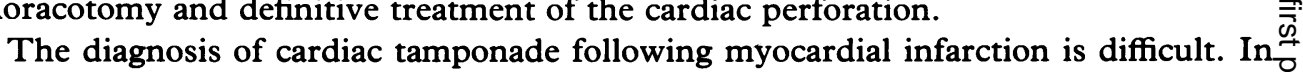
the patient with an established infarct it may be confused with cardiogenic shock. The $\frac{}{0}$ fatal outcome of the first case described illustrates the difficulty in the critically ill patient with an atypical history.

Cardiac tamponade must be kept in mind as a complication of myocardial infarction especially if the patient is presenting with severe cardiac failure.

\section{J. WARDROPE}

Department of Surgery

General Infirmary, Leeds, England

\section{REFERENCES}

Parr G. V. S., Pae W. E., Pierce W. S. \& Zelis R. (1981) Cardiogenic shock due to ventricular rupture. fournal of Thoracic and Cardiovascular Surgery 82, 889-891.

Rasmussen S., Leth A., Kjoller E. \& Pedersen A. (1979) Cardiac rupture in acute myocardial infarction. Acta Medica Scandinavica 205, 11-16. 